\title{
Foundations of Responsible Leadership: Asian Versus Western Executive Responsibility Orientations Toward Key Stakeholders
}

\author{
Michael A. Witt • Günter K. Stahl
}

Received: 7 August 2014/Accepted: 29 December 2014/Published online: 9 January 2015

(C) The Author(s) 2015. This article is published with open access at Springerlink.com

\begin{abstract}
Exploring the construct of social-responsibility orientation across three Asian and two Western societies (Germany, Hong Kong, Japan, South Korea, and the United States), we show evidence that top-level executives in these societies hold fundamentally different beliefs about their responsibilities toward different stakeholders, with concomitant implications for their understanding and enactment of responsible leadership. We further find that these variations are more closely aligned with institutional factors than with cultural variables, suggesting a need to clarify the connection between culture and institutions on the one hand and culture and social-responsibility orientations on the other.
\end{abstract}

Keywords Business systems - Culture - Institutions · Responsible leadership · Varieties of capitalism

\begin{abstract}
"Recognizing our responsibilities as industrialists, we will devote ourselves to the progress and development of society and the well-being of people through our business activities."

Konosuke Matsushita, founder of Matsushita Electric Industrial Co., Ltd.

"We are investing in environmentally-cleaner technology because we believe it will increase our
\end{abstract}

\footnotetext{
M. A. Witt ( $\square)$

INSEAD, 1 Ayer Rajah Avenue, Singapore 138676, Singapore e-mail: michael.witt@insead.edu

G. K. Stahl

Vienna University of Economics and Business, Welthandelsplatz 1, 1020 Vienna, Austria

e-mail: guenter.stahl@wu.ac.at
}

revenue, our value and our profits. ... Not because it is trendy or moral."

Jeffrey Immelt, CEO of General Electric

Responsible leadership has emerged as a major theme in management discourse. As the world recovers from major economic crisis and, some argue, a crisis of management ethics (e.g., Ghoshal 2005; Waldman and Galvin 2008), business leaders are under increasing scrutiny. Highly publicized corporate scandals and managerial misconduct have led to a sense that senior misbehavior is greater than previously suspected (Brown and Treviño 2006; Kaptein 2008). As a result, trust in business is at one of the lowest levels on record, both in the U.S. and in Europe (Edelman 2012).

Not only Western leaders, but top-level executives in non-Western countries as well have been exposed for dishonesty, greed, and unethical business practices. For instance, managerial malpractice, exacerbated by institutional and cultural factors, have been blamed for corporate scandals in South Korea (Choi and Aguilera 2009) and Japan (Tanimura and Okamoto 2013). Similarly, bribery and corruption scandals in China and India have undermined their economic and political stability. The weak legitimacy of formal institutions and attendant institutional voids in emerging-market environments have also been recognized (Khanna and Palepu 1997; Puffer et al. 2010).

The quest for responsible leadership is a response to such issues and subsequent calls for more ethical managerial conduct, and a result of changes and new demands in the global marketplace, such as increased stakeholder activism and scrutiny (e.g., Doh and Guay 2006; Husted et al. 2012). With growing socio-political and environmental challenges around the world, there is pressure from stakeholdersamong them governments, local communities, NGOs, and consumers-for corporations to engage in self-regulation and 
take more active roles as global citizens (Maak and Pless 2006; Voegtlin et al. 2012). As the growing membership of companies in the UN Global Compact and booming corporate social responsibility (CSR) initiatives indicate, more and more business leaders seek to contribute actively to the "triple bottom line" (Elkington 1997; Savitz and Weber 2006), which simultaneously considers social, environmental, and economic sustainability (i.e., "people, planet, profits").

However, despite initiatives such as the UN Global Compact and calls for business leaders to "contribute to the creation of economic and societal progress in a globally responsible and sustainable way" (EFMD 2005, p. 3), it is still contested whether corporations and their leaders have social responsibilities beyond wealth-generation (Aguilera et al. 2007; Devinney 2009; Waldman and Siegel 2008). At one extreme, classic economic constructs of the firm hold that business has no responsibility beyond making profit for shareholders (Friedman 1970); a business leader seeking "maximum long-term owner value in ethical ways" thus acts responsibly (Sternberg 1994, p. 58). At the other extreme are ethical frameworks that assume that corporations and their leaders have an obligation to act according to the needs of a wide range of constituents, thereby "acting in the service of the common good" (Crilly et al. 2008, p. 176) or as "agents of world benefit" (Pless and Maak 2009, p. 60). Clearly, as Waldman and Galvin (2008, p. 328) have noted, responsible leadership does not mean the same thing to all.

In this paper, we argue that executives in different societies hold fundamentally different beliefs about their responsibilities toward different stakeholders, with concomitant implications for their understanding and enactment of responsible leadership. We support our argument with evidence of business leaders' views about the meaning of social responsibility, obtained through in-depth interviews with senior executives from three Asian (Hong Kong, Japan, South Korea) and two Western (Germany, United States) economies. The differences manifest in our data suggest that the very meaning of "responsibility" may be subject to contextually-contingent differences in interpretation, as illustrated by the two quotes at the beginning of this article. Our results have significant implications in understanding responsible leadership, as they are linked to leaders' perceptions of the legitimacy of stakeholders, their propensity to engage in activities that contribute to social welfare, and, thus, their CSR application. We conclude by discussing the implications for research on responsible leadership and CSR practice.

\section{Leaders' Responsibility Orientations and Underlying Assumptions About the Purpose of the Firm}

Waldman and Galvin (2008) maintain that responsible leaders embrace different mindsets, which they classify according to two perspectives: a "limited economic view" emphasizing shareholder primacy, and an "extended stakeholder view." Proponents of the former assert that executive decision-making should focus exclusively on maximizing shareholder value (e.g., Levitt 1958; McCloskey 1998; Sundaram and Inkpen 2004). The most prominent advocate was the late Milton Friedman, who argued that " $[t]$ here is one and only one social responsibility of business-to use its resources and engage in activities designed to increase profits so long as it stays within the rules of the game" $(1970$, p. 6). As for corporate responsibility, this economic view suggests that unless such activities enhance profitability, spending corporate money for social purposes such as philanthropy is a misuse of corporate resources, because "the profits of a publiclyowned company are not the managers' to give away" (Crook 2005, pp. 17-18). Objectives beyond economic necessity and minimal legal or moral standards should thus be ignored, and to the extent that firms make social contributions such as paying taxes and generating employment, these outcomes are mere byproducts of good business practices.

By contrast, the extended-stakeholder perspective acknowledges CSR's normative drivers, including executives' expectations about corporate responsibilities and their own moral values, which may go beyond economic interests (Waldman and Siegel 2008). Stakeholder theory (Agle et al. 2008; Freeman 1994; Phillips et al. 2003) asks managers to make decisions cognizant of needs and demands across a broader set of constituencies, including investors, employees, consumer groups, environmentalists, and wider society. Thus, the stakeholder perspective focuses rather on relationships with constituencies, arguing that their needs must be balanced in the actions of people in positions of organizational leadership (Margolis and Walsh 2003; Sully de Luque et al. 2008).

While the shareholder-primacy and the stakeholderperspective approaches seem to represent polar opposites, attempts have been made to reconcile them. Freeman et al. (2004, p. 365) argue that "[d]ividing the world into 'shareholder concerns' and 'stakeholder concerns' is roughly the logical equivalent of contrasting 'apples' with 'fruit,' [since] shareholders are stakeholders" of the company. They note that in an era when firms rely on committed value-chain partners to deliver outstanding performance, the goal of creating value for stakeholders is decidedly pro-shareholder. In a similar vein, Waldman (in Waldman and Siegel 2008) has observed that shareholders in many firms are increasingly demanding that their firms "do well by doing good," which involves developing new business models that align social responsibility with profit maximization. The idea that organizations can profit from maximizing the benefits of multiple constituents 
concurrently is in line with the concept of shared value (Porter and Kramer 2011), which holds that companies can use their core competencies to provide solutions to social and environmental problems. While many managers believe there is an inherent trade-off between being profitable and socially responsible, research has supported the idea of shared value creation, indicating that corporate financial performance and social performance can go handin-hand (Margolis et al. 2008).

The above three orientations (shareholder primacy, extended stakeholder, and integrative approaches based on the concept of shared value) represent the range of beliefs that may be held regarding businesses' obligations to society and CSR in particular. Building on prior research on responsible leadership (Burton and Goldsby 2009; Pless et al. 2012; Voegtlin et al. 2012; Waldman and Galvin 2008), we use the term "responsibility orientation" to denote the different mindsets that corporate executives may embrace with respect to all aspects of firm activity, including, but not limited to, corporate responsibility. These mindsets are rooted in different assumptions about the purpose of the firm, which stakeholders are legitimate, and the ways in which firms should respond to stakeholder groups. In particular, we consider two dimensions of a leader's responsibility orientation: how salient or important various stakeholder groups are in the mind of a leader (e.g., is one stakeholder group given primacy over others); and the leader's attitudes toward stakeholder groups (i.e., are some groups evaluated more positively than others). We posit that the two dimensions are largely independent of each other. For instance, a senior executive may reject the objective of shareholder-wealth maximization but still consider shareholders a key constituent group.

In sum, business leaders embrace different responsibility orientations or mindsets with respect to the activities of their firms, which are rooted in different assumptions about the purpose of the firm, the set of legitimate stakeholders whose needs must be addressed, and the meaning of social responsibility in their roles as business leaders. While some executives see their primary, if not sole, obligations being to shareholders or owners and to complying with laws and regulations, others pursue a broader approach, considering the needs and interests of multiple constituencies.

Theoretical perspectives on responsible leadership are largely based on Western concepts, such as Habermas's theory of discourse ethics and deliberative democracy (Scherer and Palazzo 2007; Voegtlin et al. 2012), the Kantian distinction between "duties of perfect and of imperfect obligation" (i.e., the idea that leaders have the duty to refrain from harming others and the duty to advance the aims of others) (Stahl and Sully de Luque 2014), or the idea rooted in agency theory that good corporate governance requires executives to act as agents of shareholders
(Filatotchev and Nakajima 2014; Shleifer and Vishny 1997). It is not clear to what extent these concepts and ideas apply outside North America and Europe, specifically Asia. In this study, we consequently explore how leaders' responsibility orientations may vary across different Western and Asian societies. A better insight into cross-national variations in leaders' responsibility orientations is important if we are to better understand factors influencing senior-executive perceptions of the role of business in society and the legitimacy of stakeholder claims; the strategies and approaches available to them for addressing the needs of different stakeholder groups; and how companies and their leaders gain legitimacy and social acceptance in the various institutional environments in which they operate (Aguilera et al. 2007; Chiu and Sharfman 2011; Doh and Guay 2006).

\section{Asian and Western Orientations to Responsible Leadership: Institutional and Cultural Influences}

Senior executives' orientations to responsible leadership are likely to vary across institutional and cultural contexts. Because corporations and their leaders are embedded in different national systems, they will embrace different societal values related to CSR (Schneider et al. 2014; Waldman et al. 2006) and experience divergent degrees of internal and external pressures to engage in CSR (Aguilera and Jackson 2010; Doh and Guay 2006; Matten and Crane 2005). For instance, Martin et al. (2009), comparing business ethics between managers from Germany and the US, concluded that orientations and approaches to responsible leadership differ. They suggest that the US view has its basis in utilitarianism and emphasizes the moral responsibility of the individual, while German "Wirtschaftsethik"-which loosely translates as the ethics of relationships between economics and society-emphasizes social partnerships and companies as social entities. Germany's focus on consensual ethics can be linked to a social-market philosophy and the stakeholder system of German corporate governance, which is distinguished by cooperation and consensus and is clearly different from the shareholder capitalism common in the US.

The small but growing body of literature addressing how aspects of the national context may affect leaders' responsibility orientations and CSR-related decisions is still very much grounded in European and U.S. contexts. With notable exceptions (e.g., Chapple and Moon 2005; Choi and Aguilera 2009), little research has been done in an Asian context, and few studies have adopted a comparative perspective between Asia and the West (e.g., Witt and Redding 2012). Our study builds on and extends these works by examining how responsibility orientations, 
conceptualized in terms of the salience of specific stakeholder groups and leaders' attitudes toward these groups, may differ between and within Asia and the West, comparing three Asian [Hong Kong, Japan, South Korea (hereafter: Korea)] and two Western (Germany, United States) economies. Our specific premise is that aspects of the institutional context within which companies and their leaders operate (e.g., corporate governance) are closely related to the salience of specific stakeholder groups, whereas cultural values are more closely related to leaders' attitudes toward these groups, as discussed below.

Institutional contexts have been categorized along many dimensions (Aguilera and Jackson 2003; Brammer et al. 2012; Hall and Soskice 2001; Matten and Moon 2008; Whitley 1999; Witt and Redding 2013). Table 1 gives an overview of those dimensions that seem most relevant to leaders' perceptions of the salience of specific stakeholder groups (e.g., employees, unions, owners/shareholders) across the economies in our sample.

Hall and Soskice's (2001) work on Varieties of Capitalism suggests that nations can be divided into two types based on their institutional make-up: liberal market economies (LMEs) and coordinated market economies (CMEs). According to their typology, three of the economies in our study can be classified as CMEs (Germany, Japan, and, with some qualifications, Korea) and two as LMEs (Hong Kong and the United States). LMEs feature relatively free-market arrangements, with supply-anddemand forces having a large impact on organizational outcomes and processes. In terms of financial systems, LMEs such as Britain, Canada, and the US tend to embrace "shareholder value," with company performance measured by market value, returns evaluated on a shortterm basis and the state rarely intervening in the economy. Employment relations are characterized primarily by open labor-market relationships, firms having the freedom to hire and fire employees almost at will and collective bargaining being uncoordinated and taking place at firm level (Aguilera and Dencker 2004). In contrast, CMEs such as Germany, Japan, and Scandinavian countries are characterized by relatively strong non-market relationships. In these "stakeholder capitalism" national models, employees, suppliers, customers and financial institutions are part of the context within which business leaders make decisions and firm performance is evaluated. Firms are expected to protect employee rights, collective bargaining tends to be coordinated, and corporate returns tend to be assessed on a long-term basis (Aguilera and Dencker 2004; Aguilera and Jackson 2010; Witt and Redding 2013). In such an environment, senior executives are more likely to adopt a long-term approach to CSR and focus on a broader group of constituents in their decisions and actions.
The above suggests that the CMEs of Germany, Japan, and Korea on the one hand and LMEs of Hong Kong and the United States on the other differ on a number of key dimensions. Leaders in CMEs are likely to adopt a more comprehensive approach to responsible leadership, taking into account the claims and interests of a wider range of stakeholders, both internal and external to the firm. Thus, the breadth of constituent-group focus and degree of accountability toward stakeholders other than shareholders (e.g., employees, unions, suppliers) is likely to be higher in CMEs, and executives are more likely to pursue an approach of longer-term value creation, involving aligning the firm's interests with those of key stakeholders (Pless et al. 2012; Waldman and Galvin 2008). In contrast, leaders in LMEs will be inclined to a "limited economic" view, focusing on shareholder-value maximization and embracing instrumental ethics (Scherer and Palazzo 2007; Waldman and Siegel 2008). The needs and claims of stakeholders other than shareholders are accorded lower priority and considered only as far as they affect shareholder interests. Hence our first hypothesis:

Hypothesis 1 The responsibility orientation of senior executives in CMEs will differ from those in LMEs with respect to the salience of stakeholder groups. Executives in LMEs are more likely to give primacy to owners/shareholders, whereas executives in CMEs are more likely to consider the needs of a wider range of stakeholders, including employees, customers, and wider society.

Besides aspects of the institutional context, cultural factors are likely to play an important role in determining executives' responsibility orientations. North American, European, and Asian cultural systems have generated very different assumptions about society, business and government (Aguilera and Jackson 2010; Matten and Crane 2005; Redding et al. 2014; Redding and Witt forthcoming). Martin et al. (2009) demonstrate that differences in cultural values and beliefs create expectations of acceptable and unacceptable leader behavior, which places constraints on the types of leader behavior and characteristics endorsed in a society. On this basis, we contend that senior executives' expectations about corporate responsibilities to society and their attitudes toward specific stakeholder groups will be shaped by the dominant cultural values in the countries where they reside.

In this paper we draw on the findings of the GLOBE project (House et al. 2004; Javidan et al. 2006), a largescale study of cross-cultural leadership involving 62 societies around the world, to explore implications for responsible leadership. GLOBE developed nine dimensions for comparing the different societal cultures of the world, of which three have consistently been found to be related to responsible leadership and CSR (Husted and Allen 2008; 


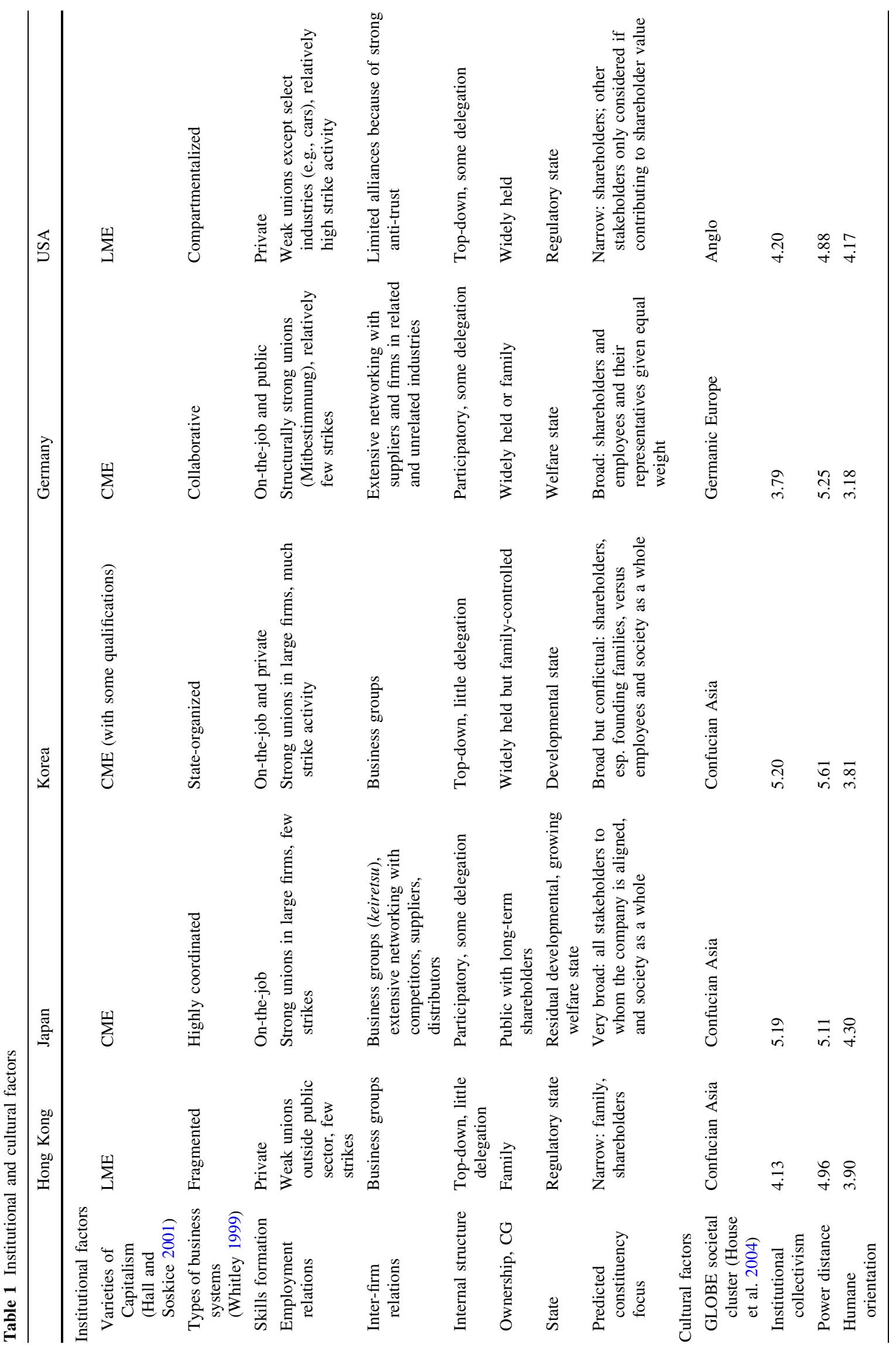


Waldman et al. 2006; Williams and Aguilera 2008): institutional collectivism, power distance, and humane orientation. For instance, in a study of 561 firms based in 15 countries on five continents, Waldman et al. (2006) examined the relationship between CSR orientations of top management and two country-level cultural dimensions, institutional collectivism and power distance. They found that managers in countries with high institutional collectivism and low power distance were more likely to manifest behaviors associated with three responsibility orientations: concern for shareholders, concern for stakeholders, and concern for community/state welfare. Importantly, their findings suggest that cultures valuing institutional collectivism promote thinking about how managerial actions pertain to the concerns of a wider range of stakeholders and wider society, whereas cultures with strong power distance values may reduce managers' concern for such stakeholders as employees, environmentalists, and customers.

Other studies have found that humane orientation explains a predisposition to engage in responsible leader behavior. Humane orientation is the degree to which a society encourages and rewards individuals for being fair, altruistic, generous, caring, and kind to others (House et al. 2004; Javidan et al. 2006). Countries with stronger humane orientation consider the interests of others, affirm belonging and affiliation, and embrace norms and responsibilities for protecting the well-being of others. Martin and his colleagues (e.g., Martin et al. 2007; Bame-Aldred et al. 2013) found that managers in countries low in humane orientation are more likely to show behaviors considered socially harmful. Humane orientation is thus likely to be positively associated with leaders' propensity to consider the needs of a broad set of stakeholders and society as a whole. The foregoing discussion suggests the following hypothesis:

Hypothesis 2 The responsibility orientation of senior executives, particularly their attitudes toward different stakeholder groups, will vary across different cultural contexts. Executives from cultures characterized by strong institutional collectivism and humane orientation and weak power distance are more likely to show concern for a wider range of stakeholders and society at large than executives from cultures characterized by weak institutional collectivism and humane orientation and strong power distance.

A critical distinction in the GLOBE project is the one between cultural values and practices. On each dimension a society is positioned in terms of both its practices ("Culture As Is"-scores) and its values ("Culture As Should Be"scores). Cultural practices data tell us something about the current perceptions, attitudes and practices of each culture, cultural values tap the respondents' feelings about their cultural aspirations and the direction the respondents want their culture to develop in the future (Javidan et al. 2006). Most studies that draw on the findings of the GLOBE project to investigate the culture-CSR link use the cultural values scores; however, since we are interested in how cultural orientations might influence senior leaders' perceptions of the role of business in society, the legitimacy of stakeholders, and the approaches available to them for addressing the needs of different stakeholder groups-and, thus "Culture As Is"-we use the GLOBE cultural practices scores to test our assumptions.

Based on the GLOBE study, all three Asian economies in this study fall into the Confucian Asia (East Asian) cluster, characterized by high institutional collectivism, moderate to high power distance, and moderate humane orientation (Javidan et al. 2006). The cultural profiles of Hong Kong, Japan, and Korea are thus distinct from both the Anglo and Germanic cultural cluster. However, as shown in Table 1, subtle differences exist among the countries of the Confucian Asia cluster. For instance, Korea has significantly higher scores on the power-distance scale than both Hong Kong and Japan; Hong Kong has the lowest scores on institutional collectivism among the three; and Japan scores significantly higher on humane orientation than Hong Kong and Korea, while also scoring high on institutional collectivism. This pattern supports the prediction that among business leaders from these Asian economies, Japanese executives will show greater concern for stakeholders other than shareholders, and society at large and its welfare, than South Korean or Hong Kong leaders. Germany and the United States differ in many respects from these Asian economies and also from each other in terms of cultural orientations. However, it is noteworthy that the United States and Hong Kong, both LMEs, have very similar scores on the GLOBE institutional collectivism, power distance, and humane orientation scales, which leads us to predict that senior executives in these two economies will exhibit similar responsibility orientations.

Based on the above, several broad generalizations can be made regarding expectations of leaders' responsibility orientations in the five economies studied here. In terms of institutional factors, we have shown that the CMEs of Germany, Japan, and Korea differ from the LMEs of Hong Kong and the United States on a number of key dimensions, including ownership, employee relations, skills formation, corporate governance, and the role of the state. These differences likely have important implications for leaders' responsibility orientations, particularly the perceived salience of stakeholder groups. For example, it might be predicted that German and Japanese business leaders will pursue an approach to responsible leadership that is longer-term and takes a wider range of stakeholders 
into account, whereas business leaders in the United States and Hong Kong will tend toward a narrower constituent focus, prioritizing shareholder interests. In addition to institutional factors, our analysis suggests that cultural values may matter as well. For instance, the specific cultural profiles of Germany (e.g., low collectivism and humane orientation) and Japan (e.g., high collectivism and humane orientation) suggest that despite some similarities of institutional context, Japanese business leaders will, more than German leaders, tend to emphasize the interests of stakeholders with whom the firm is closely aligned (such as suppliers and distributors), as well as society at large.

Below, we explore these issues empirically, comparing and contrasting the responsibility orientations of business leaders from the selected economies.

\section{Data and Methods}

Of our five economies, Germany and the United States were included as reference points of Western ways of doing business (also known as "business systems"), namely, as exemplars of its Anglo-Saxon and continental European varieties (Hall and Soskice 2001; Whitley 1999). The Asian economies feature the three major Asian types of business system (private Chinese, Japanese, and Korean) previously identified (Whitley 1992, 1999). Private Chinese business is distinct among these in that it is not territorially-bound, but extends across much of East Asia. The choice of Hong Kong as representative of this system was conditioned by prior findings that, first, there exists a common mindset among ethnic Chinese businesses in Asia (Redding 1990), and second, that the mainland Chinese mindset has at least partially converged with it, largely as a result of Hong Kong business activities in the People's Republic (Ralston et al. 2006; Redding and Witt 2007). Jointly, our sample encompasses five distinct institutional contexts-three Asian and two Western—and three cultural realms: Confucian Asian, Germanic European, and Anglo (see Table 1). The combination of institutional variation and cultural commonalities should be helpful for parceling out sources of variation in responsibility orientations.

Data collection involved interviews with 73 top-level executives, serving or recently retired, of major local firms. In line with variations in corporate governance structures, the precise definition of "top-level" varied by local context. For Hong Kong, Korea, and the US, we focused on top management teams; in Germany, on members of management and supervisory boards; and in Japan, management boards. These all have in common responsibility at the highest level for creating and executing company strategy. Most of the interviewees were chairmen, CEOs, or presidents, and thus involved in general management.
"Major firms" in our definition were those belonging to the economically dominant organizational type in the respective economy: in Germany, firms large enough to be listed, or eligible for listing, among its largest $100 \mathrm{firms}$; in Hong Kong, major listed firms; in Japan, members of the six major business groups (keiretsu); in Korea, conglomerates of various sizes, with a focus on chaebol; and in the United States, Fortune 500 firms. Seventeen executives were interviewed in Germany, 10 in Hong Kong, 17 in Japan, 15 in Korea, and 14 in the United States.

We drew on existing connections and third-party introductions to reach our interviewees. We reduced the risk of sampling bias inherent in this type of research by obtaining introductions from mutually independent contacts. Our analysis did not reveal significant within-country effects driven by known differences at the individual level, such as industries or whether the interviewee had a significant ownership stake in the company.

Given the exploratory nature of this research, we used semi-structured, in-depth interviews (Redding 1990). We conducted all interviews face-to-face, with the exception of four phone interviews with US executives. The average interview took $45 \mathrm{~min}$ in the United States and about $1 \mathrm{~h}$ elsewhere. Interviews in Germany were in German, those in Japan in Japanese except for one case, in which the interviewee chose English. All other interviews were in English. We recorded all interviews on the understanding that the data provided were not for attribution.

We used exploratory content analysis to identify the core elements of leaders' responsibility orientations. We transcribed all interviews verbatim in the respective language, then assigned to all statements relevant to the research question a category (e.g., employees, shareholders) and a value between -3 and +3 denoting attitude, as described in Table 2. Given the study's exploratory nature, we let the categories emerge from the interview data (Altheide 1987; Krippendorff 2004; Redding 1990), i.e., we did not impose a pre-defined list of categories, but added new ones as necessary.

We used a standard refereeing process to verify coding reliability and validity. Research assistants with no prior involvement in the project but the requisite language skills received a 1-h introduction to the process and a list of coding categories. They then coded randomly-selected, contiguous segments amounting to five percent of the total length of the transcripts of each geography. Statistics for intercoder agreement are summarized in Table 3. All values of Cohen's kappa are above the most demanding levels of 0.75-0.80 postulated in the methodological literature (Banerjee et al. 1999; Popping 1988).

In this paper, we focus on how executives linked their firm's rationale to various stakeholder categories, such as employees or shareholders. Since executives sometimes 
Table 2 Coding scheme for attitude

\begin{tabular}{lll}
\hline Value & Meaning & Example \\
\hline+3 & Affirmation through action & We follow the Jack Welch recipe book for maximizing shareholder value \\
+2 & Affirmation & Shareholder value is a key component of why firms exist \\
+1 & Tentative affirmation & I think shareholder value is an important factor \\
0 & Neither affirmation nor rejection & Shareholder value is neither here nor there as far as I am concerned \\
-1 & Tentative rejection & Shareholder value does not seem like something we should consider \\
-2 & Rejection & Shareholder value is not something firms should do \\
-3 & Rejection through action & We used to emphasize shareholder value, I put an end to this \\
\hline
\end{tabular}

Table 3 Intercoder reliabilities

\begin{tabular}{ll}
\hline Geography & Cohen's kappa (threshold 0.75-0.80) \\
\hline Germany & 0.91 \\
Hong Kong & 0.87 \\
Japan & 0.85 \\
Korea & 0.85 \\
USA & 0.88 \\
\hline
\end{tabular}

referred to "stakeholders" without specifying who they had in mind, we also include this category in our report. As summary statistics, for each stakeholder category in each economy, we calculated overall salience and overall attitude. Overall salience is the percentage of interviewees referring to the given stakeholder category. Overall attitude is the mean of the attitude values $(-3$ to +3$)$ assigned to all statements about the given stakeholder category in the respective economy.

\section{Results}

Table 4 presents an overview of our findings. For each economy, we report all stakeholder categories discussed by executives in descending order of salience. Average attitude values are coded using shades of gray, as marked in the table.

A caveat in the interpretation of Table 4 is that the lower the salience, the more vulnerable attitude values become to outlier opinions. This shows most clearly in the low value for creditors in the United States, based on a single negative statement by a single executive. The same concern applies to all categories with single-digit salience values, as well as the "stakeholders" category for Hong Kong. These findings are reported for the sake of completeness.

While considerable heterogeneity is suggested in terms of categories and their saliences and attitude scores, a number of patterns are visible. First, the three most salient stakeholders across all five economies are identical (though with variation in the specific order): employees, shareholders, and society form a trinity of major stakeholder categories regardless of cultural and institutional context. Second, in four of the five-Korea being the exception-customers occupy a relatively salient position in the minds of executives. However, given the gap in salience compared with the trinity categories, they seem to be secondary.

Third, the five economies seem to fall into two general groups: a shareholder-primacy group including Hong Kong and the US, which ranks owners/shareholders highest in terms of salience and holds a relatively positive attitude toward this constituent group; and an employee and society-focused group including Germany and Japan, whose attitude values suggest relatively greater affinity to employees and society than to shareholders (although owners/shareholders are seen as important constituent group). Intriguingly, these two economies are also the only ones to mention suppliers as stakeholders, which is consistent with findings on long-term reciprocal supply chain relations in these economies (cf. Witt 2006). Korea lies in between, though its relative emphasis on employees and further analysis of the interviews (see below) suggest that it may lean somewhat toward an "employee and society" focus. This dichotomous finding is noteworthy in that it mirrors the general categorization of these economies in the varieties of capitalism and business systems literatures (cf. Witt and Redding 2013), which supports Hypothesis 1. At the same time, it is inconsistent with Hypothesis 2, which suggested clustering along cultural lines and thus a clear divide between Asian and Western economies, especially in terms of senior executives' attitudes toward stakeholder groups.

We now offer a more detailed exposition of the findings for each economy. Given the caveat about outlier opinions already mentioned, we will focus on categories on which at least half the executives (or, for odd-numbered samples, $(N-1) / 2$ executives) touched.

\section{Germany}

Shareholders represented the most salient stakeholder. However, the attitude score was much lower than for any 
Table 4 Stakeholders by economy in descending order of salience

\begin{tabular}{|c|c|c|c|c|c|c|c|c|c|}
\hline Germany & & Hong Kong & & Japan & & Korea & & US & \\
\hline Shareholders & $88 \%$ & Shareholders & $60 \%$ & Society & $88 \%$ & Employees & $80 \%$ & Shareholders & $93 \%$ \\
\hline Employees & $82 \%$ & Society & $50 \%$ & Employees & $82 \%$ & Shareholders & $73 \%$ & Society & $71 \%$ \\
\hline Society & $71 \%$ & Employees & $50 \%$ & Shareholders & $76 \%$ & Society & $67 \%$ & Employees & $71 \%$ \\
\hline Customers & $41 \%$ & Customers & $30 \%$ & Customers & $59 \%$ & Stakeholders & $7 \%$ & 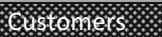 & 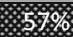 \\
\hline Stakeholders & $29 \%$ & Sthth & \% & Stakeholders & $47 \%$ & Customers & $7 \%$ & Stakeholders & $21 \%$ \\
\hline \multirow[t]{5}{*}{ Suppliers } & $24 \%$ & & & Suppliers & $18 \%$ & & & Creditors & $7 \%$ \\
\hline & & & & Creditors & $6 \%$ & & & & \\
\hline & & & & Distributors & $6 \%$ & & & & \\
\hline & & & & & & & & & \\
\hline & $\geq 2.00$ & & $\begin{array}{l}1.75- \\
1.99\end{array}$ & & $\begin{array}{l}1.25- \\
1.74\end{array}$ & & $\begin{array}{l}1.00- \\
1.24\end{array}$ & & $<1.00$ \\
\hline
\end{tabular}

Shades of gray denote attitude (cf. bottom of table). Where two or more categories share the same salience value, they are shown in descending order of attitude. Where two or more categories have both identical salience and attitude values, they are shown in alphabetical order

other category. In particular, virtually no executive favored pursuing shareholder value. The majority never mentioned shareholder value, and when the topic was discussed, interviewees typically expressed a diffident or negative view:

"I consider an exclusive focus on shareholder value, however one defines it, highly questionable."

At the same time, most executives recognized shareholders' right to decent earnings, though in some cases reluctantly:

"I do not necessarily need shareholders. After all, there are other forms of obtaining finance. ... Yet we are a corporation, and so the shareholders are decisive for us."

In the minds of German executives, shareholders are thus a stakeholder group whose interests are not primary, but coexist and at times compete with those of other stakeholders.

Employees were the second most salient stakeholder category. Key concern was the provision of employment for the benefit of both, employees and society:

"To provide work and bread for a large number of people is an extraordinarily important task. If that were not done, an entire people would be, so to speak, bread-less."

Some executives further suggested a role for their firms in letting employees develop themselves and find personal fulfillment. The third most salient stakeholder was society. The dominant mode of serving society described in interviews was through the provision of required goods and services, with some intersection with catering to customers' needs. Striking in the context of the 2008 financial crisis, for instance, is the following statement by a banker:

"A bank is anyway, next to the fact that it makes a profit, an affair that is relevant to society to the highest degree, as it offers loans, and loans are the lifeblood of an economy."
Other executives, especially from other industries, tended to point to the value of their products in facilitating social life as we know it and driving social progress through innovation:

"If you are a manufacturing firm, you should... equally bring innovation to society. And that society is provided for with products is self-evident."

Firm activities and survival are thus not at the discretion of managers and owners, but a social obligation.

All these various claims of stakeholders presented themselves in a complex web of interdependencies:

"People are not the abstract capital of the dividend. They are supposed to serve their firm so that the people in the firm flourish, and in order for them to flourish, capital has to increase to the maximum extent and has to be served properly, just as I cannot kill my suppliers."

The implication is that the firm's well-being was seen as contingent on its ability to confer benefit to all stakeholder groups.

Among executives citing several stakeholders, there was no consensus about an order of importance. Most did not state a rank order, and some even argued that even the attempt at ranking would lead to an "intellectual dead-end." To the extent rank orders were offered, they varied by interviewee, and sometimes even changed in the course of an interview. This may indicate a complex balancing act within a rationale that founds action in the maintenance of stability.

\section{Hong Kong}

The vast majority of Hong Kong executives regarded serving shareholders as a firm's primary objective. A key objective in this context was to provide wealth to the owning family: 
"[For] most business enterprises in the society, creating wealth for themselves...[for] their family members would probably be the initial driving force."

Sixty percent directly expressed the view that Hong Kong firms exist to enrich their primary shareholders. The attitude score was highly positive in general, a fact obscured in the average attitude rating because of one interviewee's critical views.

A further $30 \%$ made the same point more diplomatically by stressing the importance of shareholders and shareholder value. While formally consistent with the shareholder emphasis in much of recent international management discourse, there was a clear sense that not all shareholders are equal:

"Hong Kong families, many of them, they don't treat minority shareholders that well... They do business with their own family companies."

This practice of self-dealing among firms with the same owners has been implicated in "tunneling" profits away from minority shareholders toward firms in which ultimate owners hold the highest cash-flow rights (Cheung et al. 2006).

Wealth enables contributing to society through charity, with society being mentioned very positively by half the executives. In general, charity was portrayed as something to indulge in after becoming wealthy:

"After I make a lot of money [through the firm], then

I think social work is one of the ways I spend my money."

The picture thus drawn by our Hong Kong interviewees is consistent with a fairly narrow focus on the self-interest of controlling shareholders. Recognition of the firm's role in society was not entirely absent, though weakly developed and seemingly subject to getting rich first:

"Once [owners] reach a certain stage, probably they will be begin to think beyond creating wealth or to the stage that wealth is sufficient enough that they don't have to worry about, then they will cross to the next level of... contributing back to society."

Also weak was a sense of responsibility toward employees. There was no strong integration in the worldview of executives other than a recognition of employees as a necessary but ultimately dispensable production factor. A striking example of this was the assertion that the reason Hong Kong firms preferred labor-intensive to capitalintensive activities was that

"you can lay off half your staff, but you cannot lay off half the equipment and not bear the burden of the initial capital cost."
Japan

Japanese executives regarded serving society as a primary objective of their firm. Exemplary was the following view:

"For a manager, the most important thing is not to improve business results during one's time. Rather, I think what is extremely important is when one passes [things] on to the next manager, to what extent the firm is one whose shape is accepted by society, and one can ensure the permanence of the firm."

Serving the firm's key stakeholders emerged as the main avenue of becoming "accepted by society." Slightly less than half of the interviewees made this approach explicit, often by contrasting their approach with the perceived single-minded US focus on shareholders:

“Not like that American-style 'shareholder-only,' not that way of doing things, but managers have after all a responsibility toward all stakeholders."

Yet not all stakeholders are equal. Most important for Japanese executives were their employees:

"I think [the most important stakeholder] is the employees. Pay the shareholder a dividend within tolerable bounds."

Implicit in this and similar statements is a ranking that places employees first and sees shareholders as a constraint. As such, these statements effectively represent a reverse of the US shareholder-value approach, which places the shareholder first and pays non-executive employees an income "within tolerable bounds."

The most commonly discussed avenue of taking care of employees was through sharing economic surplus created in the firm, which in turn was taken to improve living standards and stability in private life. Several executives also considered it important for firms to contribute to the personal development and self-fulfillment of employees.

Shareholders as a stakeholder group were similarly salient in the minds of executives, but with considerably lower attitude value. In particular, there was universal rejection of US-style thinking:

"This shareholder value discussed these days is all short-term. Not like that, we look at the long term."

The notion that shareholders as owners of the company should have a right to determine its fate was explicitly rejected. Even when shareholders received recognition as a legitimate stakeholder, they were mostly seen as a constraint, as already noted: "after all, this is the era of the shareholders."

The fourth salient stakeholder was customers. In the words of one interviewee, companies strive to "do work 
that is useful for the customer by making perfect products." Serving the customer was seen not only as an objective in its own right, but also another avenue for serving society.

\section{Korea}

Korean executives portrayed an environment requiring careful balancing of stakeholders locked in fundamental conflict.

Employees emerged as the most salient stakeholders. The majority of interviewees saw employees as an end in themselves:

"[The rationale] is to make employees happy."

A minority took a more instrumental view, linking employees' hard work to more profit and thus an ability to pay higher dividends and more taxes.

About three-quarters of executives identified shareholders as important stakeholders, though with the lowest attitude value of all elements in Korea. Some executives had drawn the conclusion from the 1997/98 financial crisis that they should focus on shareholder value:

"But after IMF crisis people realized the purpose of the company is to maximize all the shareholders' value, which is quite different."

A majority, however, rejected the prioritization of shareholders. Shareholders were generally seen as only one, and not necessarily the primary, stakeholder, even if companies officially espoused shareholder value:

"Internally, I think the employees are more impor-

tant. Then the shareholders... But officially, the shareholders, of course."

A number of factors underlie this perceived need for balance. One expressed was a lack of confidence that shareholder value as a strategy was sustainable. A second driver, not explicitly discussed initially but emerging later in the interviews, was the conflictual nature of employment relations in Korea, with high levels of often violent strikes. Accordingly, a number of interviewees pointed to the need for the firm to run in the "spirit of a family" and with "more feel to it so that employees feel like they are in a very friendly organization."

The third major stakeholder mentioned was society at large. Concern with society ranged from the generic need to be a "good citizen for society" to specific notions of needing to engage in corporate charity, a topic in twothirds of the interviews:

"We have to return the profit, some of the profit back to society."
Coexisting with charity as a means of serving society was a desire to contribute to economic development, identified as still important by about half the executives. Executives espousing this view pointed to a need to support the nation by aiding further development:

"Still we have low levels of income..., so we are still eager to focus on the economic growth, development."

While both approaches to serving society, charity and development, coexisted, the relatively higher age of executives espousing the latter suggests that this may disappear over time, leaving charity as the main avenue. Unspoken was the driver underlying both approaches, namely, a need to placate a Korean public increasingly hostile to the power and wealth of large conglomerates (cf. Witt 2014).

\section{United States}

A large majority of our interviewees identified the pursuit of shareholder value as a firm's rationale. US interviewees frequently began with this point and tended to use similar language to the following:

"[The reason,] it's shareholder return."

The one executive not to mention shareholder value did so in the context of a discussion of the US mindset in general, which took this interview to a higher conceptual level than others.

Other stakeholders cited were customers, employees, and society, the last often in terms of local communities. These were, however, clearly subordinate to shareholder interests:

"The primary objective being a shareholder objective, leads some secondary objectives which are all about, you know, satisfying products, happy customers, a community that uses them as a reasonable participant in the community."

As a result, providing benefits to these other stakeholder groups tended to be seen primarily as means toward the larger end of shareholder value. As regards employees, for instance, ensuring that "employees are appropriately paid" was important to obtaining their cooperation. One executive elaborated:

"You can't just do anything in order to increase shareholder value... Because ultimately if you are hurting your employees, ... you are not going to create a lot of shareholder value."

Likewise, serving society was not a goal in itself, but society was a stakeholder "to be very conscious of-as long as there is some benefit to the bottom line:" 
"You want to be a good citizen in the community, but not because good citizenship is good, but because if you are not a good citizen, you will be punished and you will not be able to make a profit for your shareholders."

Main avenues of service to society identified were the creation of employment and the provision of "an essential product or service that is either needed or desired by the population." Proponents of the latter, productionist, view tended to be older, suggesting that their views may be consistent with how executives viewed the world before the arrival of shareholder-value dominance (cf. Fligstein 2001).

Similarly, US executives tended to view customers as secondary to shareholders:

"I don't believe you want to satisfy your customers in and of itself, you want to satisfy your customers because that is what you have to do to make a profit from your customers."

Accordingly, profits were seen as more important than customers, lest "new owners will come in and they will say, we will give less to the customers, because you are giving stuff to the customers that isn't getting paid for."

\section{Discussion}

Based on interviews with 73 senior executives from three Asian (Hong Kong, Japan, South Korea) and two Western (Germany, United States) economies, we have shown that executives' responsibility orientations - the way they make sense of what they are doing and how they see their responsibility to the firm's stakeholders and wider society-vary considerably both between and within Asian societies and the West. The overall picture is broadly consistent with the varieties of capitalism literature dichotomously distinguishing LMEs (Hong Kong, US) and CMEs (Germany, Japan, and arguably Korea). Of course, there is variance within these broad categories, and further forms beyond these two are possible and even likely if more economies are sampled.

These differences have important implications for managerial decision-making and the enactment of responsible leadership, as they affect leaders' understanding of the meaning of social responsibility in their roles as business leaders, perceptions of the legitimacy of stakeholder groups, and their propensity to engage in activities that contribute to the welfare of their various stakeholders, including shareholders, employees, customers, and wider society (Burton and Goldsby 2009; Pless et al. 2012; Waldman and Galvin 2008).
In light of the fundamental differences in views and opinions expressed by interviewees, it is tempting to conclude that the cross-societal variations in leaders' responsibility orientations found in this study are not so much about actors playing the same game by different rules, but about business leaders in different societies playing entirely different games or having fundamentally different assumptions about the deeper purposes behind the game. Although a large majority of executives in each economy agreed on the importance of taking stakeholders into account when making decisions, those in different economies had very different ideas about how and why firms contribute to society and the meaning of responsibility in their roles of business leaders. Also, our interview findings suggest significant cross-societal variation along several key dimensions of responsible leadership, including the extent to which executives embrace a "limited economic" versus "extended stakeholder" view (Sully de Luque et al. 2008; Waldman and Galvin 2008); have a narrow versus broad constituent-group focus (Pless et al. 2012); and take a more instrumental versus values-driven approach to corporate responsibility (Palazzo and Scherer 2006; Voegtlin et al. 2012).

In addition to the key dimensions of responsible leadership advanced in the literature, we found it useful to consider the attitudes that senior executives expressed toward different stakeholders. While all average attitude values reported are positive in value, we found a wide range in the degree of positiveness. For example, we found that executives in all five societies regarded shareholders as a key stakeholder, with most interviewees referring to them; however, attitudes varied significantly. At one extreme, we saw a tendency among Japanese and German executives to reject shareholder primacy, and indeed the right of shareholders to become involved in the running of the company. As a result of these negative qualifications of executives' general agreement that shareholders mattered, average attitudes toward shareholders in these economies were at 1 or below. At the other extreme, the vast majority of US executives expressed a positive view of shareholder primacy and identified the pursuit of shareholder value as the firm's principal rationale. Similarly, executives in all five economies identified employees as an important stakeholder group, but with considerable variation in attitude. Hong Kong, followed by US, executives were least positive, even viewing employees as an expense or problem. By contrast, executives in Japan, Korea and Germany identified employees' well-being as a firm's key objective and tended toward positive attitudes regarding this stakeholder group.

These findings illustrate significant cross-societal variations in leaders' responsibility orientations-i.e., their attitudes toward legitimate stakeholders and in what ways 
firms should respond to each stakeholder group. However, these differences do not align neatly with existing cultural clusters like those identified in the GLOBE project (House et al. 2004; Javidan et al. 2006). For example, the above discussion suggests that in terms of stakeholder orientation and corporate responsibility, Germany and Japan seem to have more in common than Japan and other East Asian societies. This is consistent with a recent study (Witt and Redding 2013) that found that Germany and Japan, despite significant differences in national culture, are closer in terms of institutional practices than countries sharing a common cultural heritage, such as Germany and the United States, or Japan and Korea.

The presence and absence of alignment with institutional and cultural factors, respectively, poses important questions about the relationship between culture and institutions. Thus far we have treated institutional characteristics and cultural factors as if separate antecedents of leaders' responsibility orientations. However, aspects of the institutional environment and cultural traits are probably interdependent and mutually reinforcing (Redding and Witt 2007; Redding 2008). As Aguilera and Jackson (2010, p. 504) put it, "[c]ulture and institutions are historically intertwined in ways where it makes little sense to draw causal arrows between artificially divided cultural and institutional variables." This implies that no single cultural dimension or institutional characteristic (or limited set of cultural and institutional factors) is likely to predict or explain differences in leaders' responsibility orientations across countries.

In interpreting our findings, it is further important to consider that the cultural and institutional contexts of firms (and managerial decision-making) are not static, but subject to dynamic and emergent processes. Furthermore, the relationship between national context and leaders' approaches to CSR is mutual and reciprocal, with leaders able to foster structural change, for instance, by facilitating collective action. As Witt and Redding (2012, p. 110) have pointed out, "senior executives are in powerful positions to subvert and shape the institutional structures in which firms are embedded, including those related to CSR." The way Korean executives responded to social pressure toward corporate responsibility in the wake of the 1997/1998 Asian financial crisis is instructive in this regard. Choi and Aguilera (2009) showed how the crisis, which impacted Korean conglomerates severely, introduced CSR concepts to Korean society. It prompted local actors to rethink the role and responsibilities of corporations in society, leading to improved corporate governance and more responsible leader behavior. Korean managers were thus 'forced' to develop a stronger responsibility orientation and to consider the claims of a larger group of stakeholders for instrumental reasons, including restoring their damaged reliability and reputation.
Limitations and Implications for Research

This study provides important insights into the international variety of responsibility orientations among top executives of major firms. Like all studies, it has limitations, while opening up several avenues for future investigation.

First, the data presented here are based on five relatively small, non-random samples, which implies a risk of sampling bias. We mitigated this risk partially through independent introductions to interviewees. Still, to better understand the limits of generalizability in the findings, this study should be replicated using a larger sample of individuals and organizations, and comparing leaders' responsibility orientations across a diverse range of cultural and institutional contexts.

Second, since our level of analysis was the entire economy, this study cannot provide much insight in variations in responsibility orientations as they may exist at the level of the industry or the firm. Factors such as levels of competition, turbulence, or capital and labor intensities may affect responsibility orientations. Studying these variations would require a much larger sample than our, especially if the goal is to make comparisons across countries at the industry level. This study was not designed to do this, and given the extreme difficulty of getting access to interviewees of the caliber studied in our paper, we are not sure it is feasible.

Third, while the present results are suggestive in terms of a possible link between the type of business system present in a given economy and responsibility orientation, they are not conclusive. Future research should explore social-responsibility orientations in economies with similar business systems, such as that of the Regional Ethnic Chinese of Southeast Asia or that of Germany and the northern Continental European economies. High levels of similarity within these areas would underline the importance of institutional influences.

Fourth, further research may shed light on the linkage between cultural practices and values, such as those identified by the GLOBE project (House et al. 2004; Javidan et al. 2006), and leaders' orientations and approaches to CSR. Much evidence indicates that culture matters in responsible leadership and ethical behavior, but how, when, and why are less clear. For instance, past research has found significant cultural differences in managers' willingness to accept bribery as the price of business, and willingness to engage in other forms of unethical conduct (e.g., Jing and Graham 2008; Martin et al. 2007). However, as culture is often correlated with other socio-economic influences such as GDP and institutions, it is difficult to determine which country-level factors are driving corrupt behavior. The evidence thus fails to show whether some 
cultures are more or less ethical or responsible than others (O'Fallon and Butterfield 2005).

Finally, future research should focus on the linkage between espoused values about responsibility orientations held by interviewees and their decisions and actions. Ghoshal (2005) implied that the extent to which executives embrace a "limited economic" versus an "extended stakeholder" view will affect the enactment of responsible leadership and the long-term viability of their companies, but little research has been conducted on how managers' responsibility orientation relates to actual behavior. Burton and Goldsby (2009) found that business owners translated CSR-related attitudes and orientations into behavior fairly directly. Those who embraced a "limited economic" view tended to concentrate on shareholders' interests and profitrelated goals; those placing more emphasis on non-economic domains concentrated on the interests of a larger group of stakeholders and community-related goals. This suggests that leaders' responsibility orientation might be a proxy for the behavior side of responsible leadership and corporate social performance. More research is needed to examine how leaders' values and orientations affect their propensity to engage in activities that contribute to the welfare of their various stakeholders, and how these processes vary across different cultural and institutional contexts.

\section{Implications for Practice}

The growing literature on international CSR has identified three prototypical approaches to corporate responsibility and sustainability in global corporations that affect a firm's CSR performance. Based on the tensions and possible trade-offs between globally integrated and locally adapted strategies, companies may adopt a "global CSR approach", a "local CSR approach," or a "transnational CSR approach" (Arthaud-Day 2005; Husted and Allen 2006; Stahl et al. 2013). The viability of the globally standardized approach rests on the assumption of a universal standard of responsible behavior that transcends the norms and values of particular societies. Our findings challenge the existence of such universal standards. Thus, a global CSR approach may lead to cultural arrogance and ethical imperialism, directing executives to impose their values on others and act everywhere in the way things are done at headquarters (Donaldson 1996). However, locally-oriented CSR is also problematic, as it makes it difficult to apply any universally accepted code of conduct or even to determine what is responsible or acceptable (Stahl et al. 2013). In light of the significant cross-national differences found in this study, and the simultaneous need for companies to ensure consistency with respect to their CSR activities across the organization, it seems that the transnational approach is best able to help companies coordinate their world-wide CSR activities and promote responsible leadership in the organization.

Acknowledgments We thank Deborah Poff and the anonymous reviewers for their editorial guidance and feedback. We are grateful to Gordon Redding for initiating the project underlying the data used in this paper, and to Emilio Manso-Salinas for conducting some of the interviews. We further thank the interviewees for their precious time and insights and the Lee Foundation of Singapore for funding the field research for this paper.

Open Access This article is distributed under the terms of the Creative Commons Attribution License which permits any use, distribution, and reproduction in any medium, provided the original author(s) and the source are credited.

\section{References}

Agle, B. R., Donaldson, T., Freeman, R. E., Jensen, M. C., Mitchell, R. K., \& Wood, D. J. (2008). Dialogue: Toward superior stakeholder theory. Business Ethics Quarterly, 18(2), 153-190.

Aguilera, R. V., \& Dencker, J. C. (2004). The role of human resource management in cross-border mergers and acquisitions. International Journal of Human Resource Management, 15(8), 1355-1370.

Aguilera, R. V., \& Jackson, G. (2003). The cross-national diversity of corporate governance: Dimensions and determinants. Academy of Management Review, 28(3), 447-465.

Aguilera, R. V., \& Jackson, G. (2010). Comparative and international corporate governance. The Academy of Management Annals, 4(1), 485-556.

Aguilera, R. V., Rupp, D. E., Williams, C. A., \& Ganapathi, J. (2007). Putting the s back in corporate social responsibility: A multilevel theory of social change in organizations. Academy of Management Review, 3, 836-863.

Altheide, D. L. (1987). Ethnographic content analysis. Qualitative Sociology, 10, 65-77.

Arthaud-Day, M. L. (2005). Transnational corporate social responsibility: A tri-dimensional approach to international CSR Research. Business Ethics Quarterly, 15, 1-22.

Bame-Aldred, C. W., Cullen, J. B., Martin, K. D., \& Parboteeah, K. P. (2013). National culture and firm-level tax evasion. Journal of Business Research, 66(3), 390-396.

Banerjee, M., Capozzoli, M., McSweeney, L., \& Sinha, D. (1999). Beyond kappa: A review of interrater agreement measures. Canadian Journal of Statistics, 27, 3-23.

Brammer, S., Jackson, G., \& Matten, D. (2012). Corporate social responsibility and institutional theory: New perspectives on private governance. Socio-Economic Review, 10, 3-28.

Brown, M., \& Treviño, L. K. (2006). Ethical leadership: A review and future directions. The Leadership Quarterly, 17, 595-616.

Burton, B. K., \& Goldsby, M. (2009). Corporate social responsibility orientation, goals, and behavior. Business and Society, 48(1), 88-104.

Chapple, W., \& Moon, J. (2005). Corporate social responsibility (CSR) in Asia: A seven-country study of CSR website reporting. Business and Society, 44(4), 415-441.

Cheung, Y.-L., Rau, P. R., \& Stouraitis, A. (2006). Tunneling, propping, and expropriation: Evidence from connected party transactions in Hong Kong. Journal of Financial Economics, 82, 343-386.

Chiu, S.-C., \& Sharfman, M. (2011). Legitimacy, visibility, and the antecedents of corporate social performance: An investigation of 
the instrumental perspective. Journal of Management, 37(6), $1558-1585$.

Choi, S., \& Aguilera, R. V. (2009). Corporate social responsibility dynamics in South Korea and Japan: A comparative analysis. In C. A. Mallin (Ed.), Corporate social responsibility: A case study approach (pp. 123-147). Cheltenham: Elgar.

Crilly, D., Schneider, S. C., \& Zollo, M. (2008). Psychological antecedents to socially responsible behavior. European Management Review, 5, 175-190.

Crook, C. (2005). The good company: A survey of corporate social responsibility. The Economist, 22, 3-18.

Devinney, T. M. (2009). Is the socially responsible corporation a myth? The good, bad and ugly of corporate social responsibility. Academy of Management Perspectives, 23(2), 44-56.

Doh, J. P., \& Guay, T. R. (2006). Corporate social responsibility, public policy, and NGO activism in Europe and the United States: An institutional-stakeholder perspective. Journal of Management Studies, 43(1), 47-73.

Donaldson, T. (1996). Values in tension: Ethics away from home. Harvard Business Review, 74, 48-62.

Edelman. (2012). Executive summary: 2012 Edelman Trust Barometer. Retrieved December 03, 2013, from http://de.scribd.com/doc/ 121501475/Executive-Summary-2012-Edelman-Trust-Barometer.

EFMD. (2005). Globally responsible leadership: A call for engagement. Retrieved October 18, 2005 from www.efmd.org/html/ Responsibility/cont_detail.asp?id=041207trlv\&aid=051012qnis\& tid $=1 \&$ ref $=$ ind .

Elkington, J. (1997). Cannibals with forks: the triple bottom line of 21 st century business. Oxford: Capstone.

Filatotchev, I., \& Nakajima, C. (2014). Corporate governance, responsible managerial behavior, and CSR: Organizational efficiency versus organizational legitimacy? Academy of Management Perspectives, 28, 289-306.

Fligstein, N. (2001). The architecture of markets: An economic sociology of twenty-first-century capitalist societies. Princeton, NJ: Princeton University Press.

Freeman, R. E. (1994). The politics of stakeholder theory. Business Ethics Quarterly, 4(4), 409-421.

Freeman, R. E., Wicks, A. C., \& Parmar, B. (2004). Stakeholder theory and "the corporate objective revisited". Organizational Science, 15(3), 364-369.

Friedman, M. (1970). The social responsibility of business is to increase its profits. New York Times Magazine. September, 13.

Ghoshal, S. (2005). Bad management theories are destroying good management practices. Academy of Management Learning and Education, 4, 75-91.

Hall, P. A., \& Soskice, D. (2001). An introduction to varieties of capitalism. In P. A. Hall \& D. Soskice (Eds.), Varieties of capitalism: The institutional foundations of comparative advantage (pp. 1-68). Oxford: Oxford University Press.

House, R., Hanges, P. J., Javidan, M., Dorfman, P. W., \& Gupta, V. (2004). Culture, leadership, and organizations: The GLOBE study of 62 societies. Thousand Oaks, CA: Sage Publications.

Husted, B. W., \& Allen, D. B. (2006). Corporate social responsibility in the multinational enterprise: Strategic and institutional approaches. Journal of International Business Studies, 37(6), 838-849.

Husted, B. W., \& Allen, D. B. (2008). Toward a model of crosscultural business ethics: The impact of individualism and collectivism on the ethical decision-making process. Journal of Business Ethics, 82, 293-305.

Husted, B. W., Allen, D. B., \& Kock, N. (2012). Value creation through social strategy. Thousand Oaks: Sage Business \& Society.

Javidan, M., House, R. J., Dorfman, P. W., Hanges, P. J., \& Sully de Luque, M. (2006). Conceptualizing and measuring cultures and their consequences: a comparative review of GLOBE's and
Hofstede's approaches. Journal of International Business Studies, 37(6), 897-914.

Jing, R., \& Graham, J. L. (2008). Values versus regulations: How culture plays its role. Journal of Business Ethics, 80, 791-806.

Kaptein, M. (2008). Developing a measure of unethical behavior in the workplace: A stakeholder perspective. Rotterdam: Erasmus Research Institute of Management, Erasmus University.

Khanna, T., \& Palepu, K. G. (1997). Why focused strategies may be wrong for emerging markets. Harvard Business Review, 75(4), $41-51$.

Krippendorff, K. (2004). Content analysis: An introduction to its methodology (2nd ed.). Thousand Oaks, CA: Sage Publications.

Levitt, T. (1958). The dangers of social responsibility. Harvard Business Review, 36, 41-50.

Maak, T., \& Pless, N. M. (2006). Responsible leadership in a stakeholder society-A relational perspective. Journal of Business Ethics, 66, 99-115.

Margolis, J. D., Elfenbein, H. A., \& Walsh, J. (2008). Do well by doing good? Don't count on it. Harvard Business Review, 86, $19-21$.

Margolis, J. D., \& Walsh, J. P. (2003). Misery loves companies: Rethinking social initiatives by business. Administrative Science Quarterly, 48, 268-305.

Martin, K. D., Cullen, J. B., Johnson, J. L., \& Parboteeah, K. P. (2007). Deciding to bribe: A cross-level analysis of firm and home country influences on bribery activity. Academy of Management Journal, 50(6), 1401-1422.

Martin, G. S., Resick, C. J., Keating, M. A., \& Dickson, M. W. (2009). Ethical leadership across cultures: A comparative analysis of German and US perspectives. Business Ethics: A European Review, 18(2), 127-144.

Matten, D., \& Crane, A. (2005). Corporate citizenship: Toward an extended theoretical conceptualization. The Academy of Management Review, 30, 166-179.

Matten, D., \& Moon, J. (2008). "Implicit" and "explicit" CSR: A conceptual framework for a comparative understanding of corporate social responsibility. Academy of Management Review, 33(2), 404-424.

McCloskey, D. (1998). The rhetoric of economics. Madison: University of Wisconsin Press.

O'Fallon, M. J., \& Butterfield, K. D. (2005). A review of the empirical ethical decision-making literature, 1996-2003. Journal of Business Ethics, 59, 375-413.

Palazzo, G., \& Scherer, A. G. (2006). Corporate legitimacy as deliberation: A communicative framework. Journal of Business Ethics, 66, 71-88.

Phillips, R., Freeman, R. E., \& Wicks, A. (2003). What stakeholder theory is not. Business Ethics Quarterly, 13(4), 479-502.

Pless, N. M., \& Maak, T. (2009). Responsible leaders as agents of world benefit: Learnings from "Project Ulysses" “. Journal of Business Ethics, 85, 59-71.

Pless, N., Maak, T., \& Waldman, D. A. (2012). Different approaches toward doing the right thing: Mapping the responsibility orientations of leaders. Academy of Management Perspectives, 26, 51-65.

Popping, R. (1988). On agreements indices for nominal data. In W. E. Saris \& I. N. Gallhofer (Eds.), Sociometric research: Volume I, data collection and scaling (pp. 90-105). New York: St. Martin's.

Porter, M. E., \& Kramer, M. R. (2011). Creating shared value: How to reinvent capitalism-And unleash a wave of innovation and growth (pp. 2-17). Watertown: Harvard Business Review.

Puffer, S., McCarthy, D., \& Boisot, M. (2010). Entrepreneurship in Russia and China: The impact of formal institutional voids. Entrepreneurship Theory and Practice, 34(3), 441-467.

Ralston, D. A., Pounder, J., Lo, C. W. H., Wong, Y.-Y., Egri, C. P., \& Stauffer, J. (2006). Stability and change in managerial work 
values: A longitudinal study of China, Hong Kong, and the U.S. Management and Organization Review, 2, 67-94.

Redding, S. G. (1990). The spirit of Chinese capitalism. Berlin: Walter de Gruyter.

Redding, G. (2008). Separating culture from institutions: the use of semantic spaces as a conceptual domain and the case of China. Management and Organization Review, 4, 257-289.

Redding, G., Bond, M. H., \& Witt, M. A. (2014). Culture and the business systems of Asia. In M. A. Witt \& G. Redding (Eds.), The Oxford handbook of Asian business systems. Oxford: Oxford University Press.

Redding, G., \& Witt, M. A. (2007). The future of Chinese capitalism: Choices and chances. Oxford: Oxford University Press.

Redding, G., \& Witt, M. A. (forthcoming). Advancing indigenous management theory: Executive rationale as an institutional logic. Management and Organization Review.

Savitz, A., \& Weber, W. (2006). The triple bottom line: How today's best-run companies are achieving economic. Josseybass: Social and Environmental Success.

Scherer, A. G., \& Palazzo, G. (2007). Toward a political conception of corporate responsibility. Business and society seen from a Habermasian perspective. Academy of Management Review, 32, 1096-1120.

Schneider, S., Barsoux, J.-L., \& Stahl, G. K. (2014). Managing across cultures (3rd ed.). London: Prentice Hall Financial Times.

Shleifer, A., \& Vishny, R. W. (1997). A survey of corporate governance. Journal of Finance, 52, 737-783.

Stahl, G. K., Pless, N., \& Maak, T. (2013). Responsible global leadership. In M. Mendenhall, J. Osland, A. Bird, G. Oddou, M. Maznevski, \& G. K. Stahl (Eds.), Global leadership: Research, practice and development (2nd ed., pp. 240-259). London: Routledge.

Stahl, G. K., \& Sully de Luque, M. (2014). Antecedents of responsible leader behavior: A research synthesis, conceptual framework, and agenda for future research. Academy of Management Perspectives, 28, 235-254.

Sternberg, E. (1994). Just business: Business ethics in action. London: Little, Brown and Company.

Sully de Luque, M. S., Washburn, N. T., Waldman, D. A., \& House, R. J. (2008). Unrequited profit: How stakeholder and economic values relate to subordinates' perceptions of leadership and firm performance. Administrative Science Quarterly, 53, 626-654.

Sundaram, A. K., \& Inkpen, A. C. (2004). The corporate objective revisited. Organization Science, 15(3), 350-363.
Tanimura, J. K., \& Okamoto, M. G. (2013). Reputational penalties in Japan: Evidence from corporate scandals. Asian Economic Journal, 27(1), 39-57.

Voegtlin, C., Patzer, M., \& Scherer, A. G. (2012). Responsible leadership in global business: A new approach to leadership and its multi-level outcomes. Journal of Business Ethics, 105(1), $1-16$.

Waldman, D. A., \& Galvin, B. M. (2008). Alternative perspectives of responsible leadership. Organizational Dynamics, 37(4), 327-341.

Waldman, D. A., \& Siegel, D. (2008). Defining the socially responsible leader. The Leadership Quarterly, 19, 117-131.

Waldman, D. A., Sully de Luque, M., Washburn, N., \& House, R. J. (2006). Cultural and leadership predictors of corporate social responsibility values of top management: A GLOBE study of 15 countries. Journal of International Business Studies, 37, 823-837.

Whitley, R. (1992). Business systems in East Asia: Firms, markets and societies. London: Sage Publications.

Whitley, R. (1999). Divergent capitalisms: The social structuring and change of business systems. Oxford: Oxford University Press.

Williams, C. A., \& Aguilera, R. V. (2008). Corporate social responsibility in comparative perspective. In A. Crane, A. McWilliams, D. Matten, J. Moon, \& D. Siegel (Eds.), Oxford handbook of corporate social responsibility (pp. 452-472). Oxford: Oxford University Press.

Witt, M. A. (2006). Changing Japanese capitalism: Societal coordination and institutional adjustment. Cambridge: Cambridge University Press.

Witt, M. A. (2014). South Korea: Plutocratic state-led capitalism reconfiguring. In M. A. Witt \& G. Redding (Eds.), The Oxford handbook of Asian business systems. Oxford: Oxford University Press.

Witt, M. A., \& Redding, G. (2012). The spirits of corporate social responsibility: Senior executive perceptions of the role of the firm in society in Germany, Hong Kong, Japan, South Korea and the USA. Socio-Economic Review, 10(1), 109-134.

Witt, M. A., \& Redding, G. (2013). Asian business systems: Institutional comparison, clusters and implications for Varieties of Capitalism and business systems theory. Socio-Economic Review, 11(1), 265-300. 